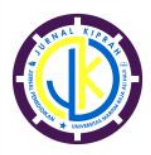

ISSN (online): 2580-6947

ISSN (print): 2354-7278

http://ojs.umrah.ac.id/index.php/kiprah/

\title{
Kemampuan Mahasiswa PGSD dalam Merancang dan Melaksanakan Pembelajaran Berbasis High Order of Thinking Skills
}

\author{
Eko Kuntarto $^{1^{*}}$, Alirmansyah ${ }^{2}$, Agung Rimba Kurniawan ${ }^{3}$ \\ ${ }^{1,2,3}$ Universitas Jambi, Muara Bulian, Jambi 36613, Indonesia
}

Pengiriman: 5 September 2019; Diterima: 9 Oktober 2019; Publikasi: 25 November 2019

\begin{abstract}
Abstrak
Hasil survei badan dunia di bidang menulis, matematika, dan sains sebagai ukuran kemajuan literasi, hasilnya menunjukkan kemampuan berpikir tingkat tinggi atau High Order of Thinking Skills (HOTS) siswa di Indonesia rendah dan diperingkat 69 dari 76 negara. Hasil tersebut menjadi refleksi bagi pembaruan sistem pembelajaran di LPTK, termasuk mahasiswa program studi Pendidikan Guru Sekolah Dasar (PGSD). Penelitian ini adalah penelitian deskriptif karena mendeskripsikan kemampuan mahasiswa PGSD dalam merencanakan dan melaksanakan pembelajaran berbasis HOTS di SD. Responden berjumlah 154 orang. Instrumen yang digunakan yaitu lembar observasi, Lembar angket dan Tes. Teknik analisis data kuantitatif-kualitatif atau disebut strategi metode campuran konkuren (concurrent mix method). Hasil penelitian menunjukkan kemampuan dalam pengetahuan dasar pembelajaran HOTS masih rendah hanya 52,24\% yang lulus. Sisanya, 47,76\% tidak memenuhi Kriteria Ketuntasan Minimal (KKM). Aspek merencanakan pembelajaran HOTS masih rendah, hanya 59,58\% mahasiswa memenuhi KKM. Aspek kemampuan melaksanakan pembelajaran berbasis HOTS, 49,03\% mahasiswa tidak memenuhi KKM. Aspek merancang dan melaksanakan penilaian berbasis HOTS, 51,30\% tidak mencapai KKM. Simpulan penelitian, mayoritas mahasiswa belum menunjukkan kemampuan yang baik dalam merencanakan dan melaksanakan pembelajaran HOTS di SD.
\end{abstract}

Kata Kunci: PGSD, HOTS, pembelajaran, SD

\begin{abstract}
The results of a survey of the world body in the fields of writing, mathematics, and science as a measure of literacy progress, the results show the ability to think of high level or High Order of Thinking Skills (HOTS) students in Indonesia is low and ranked 69 out of 76 countries. The results are a reflection of the renewal of the learning system in LPTK, including students in the Primary School Teacher Education (PGSD) study program. This research is a descriptive study because it describes the ability of PGSD students in planning and implementing HOTS-based learning in elementary schools. Respondents totaled 154 people. The instruments used were observation sheets, questionnaire sheets and tests. Quantitative-qualitative data analysis technique or called concurrent mix method. The results showed the ability in basic knowledge of HOTS learning was still low, only 52.24\% had passed. The remaining 47.76\% did not meet the Minimum Mastery Criteria (KKM). The aspects of planning HOTS learning are still low, only $59.58 \%$ of students meet the KKM. Aspects of the ability to carry out HOTS-based learning, $49.03 \%$ of s tudents do not meet the KKM. In the aspect of designing and implementing HOTS-based assessment, $51.30 \%$ did not reach the KKM. Conclusions of the study, the majority of students have not demonstrated good skills in planning and implementing HOTS learning in elementary schools.
\end{abstract}

Keywords: PGSD, HOTS, learning, elementary school 


\section{JURNAL KIPRAH. November 2019; 7 (2): 107-116 \\ ISSN (online): 2580-6947 \\ ISSN (print): 2354-7278}

\section{Pendahuluan}

Hasil survei badan dunia, yakni Programme for International Student Assessement (PISA) tahun 2015, yang meneliti kemampuan masyarakat di 72 negara di dunia pada 3 bidang, yakni menulis, matematika, dan sains sebagai ukuran kemajuan literasi menunjukkan adanya peningkatan kemampuan siswa Indonesia. Dibandingkan dengan hasil PISA tahun 2012, kemampuan membaca siswa Indonesia telah meningkat dari 337 menjadi 350, kemampuan matematika meningkat dari 318 menjadi 335, dan kemampuan sains meningkat pesat dari 327 poin pada tahun 2012, menjadi 359 di tahun 2015. Dari data PISA tersebut terlihat kemampuan siswa Indonesia tersebut masih berada di bawah rata-rata dibandingkan 72 negara lainnya.

Pada implementasi kurikulum 2013 di sekolah dasar, guru diharapkan dapat mengembangkan perencanaan dan pelaksaanaan pembelajaran yang menunjang keterampilan bertanya yang berorientasi pada kemampuan berpikir tingkat tinggi. Pada buku guru telah dipaparkan bahwa aktivitas minggu ke empat merupakan kegiatan proyek dan literasi yang bertujuan untuk meningatkan keterampilan berpikir tingkat tinggi dan keterampilan membaca siswa dan rasa cinta membaca (Kemendikbud, 2017) Hingga akhir tahun ajaran 2018, Kurikulum 2013 telah berjalan selama 4 tahun sejak tahun 2013. Kurikulum 2013 telah diterapkan sejak jenjang sekolah dasar sampai SMA/SMK di seluruh Indonesia. Oleh karena itu, Lembaga Pendidikan Tenaga Kependidikan (LPTK) sebagai penghasil lulusan calon guru di Indonesia sudah seharusnya mulai berbenar diri, mengikuti kebijakan pengembangan K-13 di sekolah, agar kemampuan mahasiswa calon guru dalam mengajar sejalan dengan perbaikan sistem pembelajaran yang tengah diupayakan oleh pemerintah.

Dalam kaitannya dengan Program Studi Pendidikan Guru Sekolah Dasar (PGSD), yang menghasilkan calon Guru SD, rendahnya hasil penelitian PISA patut menjadi perhatian tersendiri. Survei PISA yang merupakan sistem ujian yang diinisisi oleh Organisation for Economic Co-operation and Development (OECD) digunakan untuk mengevaluasi sistem pendidikan pada siswa berusia 15 tahun atau siswa kelas IX atau $\mathrm{X}$ di Indonesia. Hal itu berarti, sasaran PISA adalah siswa SMP, yang "notabene" lulusan SD.

Wijayanti, Pudjawan, dan Margunayasa (2015) memberikan penguatan bahwa jika kemampuan berpikir kritis ini telah dilatihkan di SD maka manfaatnya akan dirasakan oleh peserta didik ketika berada di jenjang pendidikan yang lebih tinggi. Hal ini sejalan dengan pendapat Lapono (Lapono, dkk., 2010) bahwa keberhasilan individu dalam penguasaan dasardasar keterampilan berpikir pada tahap perkembangan remaja (middle childhood) berpengaruh pada tahap perkembangan saat mereka dewasa (adolescene). Hal tersebut berarti keberhasilan akademik individu pada jenjang pendidikan yang lebih tinggi sangat ditentukan oleh keberhasilannya dalam kegiatan akademik atau belajar pada jenjang pendidikan dasar (SD).

Berkaitan dengan hal tersebut, hal penting yang perlu diperhatikan adalah proses dan muatan pembelajaran di Fakultas Keguruan dan Ilmu Pendidikan (FKIP). Mahasiswa FKIP perlu diperkenalkan sistem pembelajaran yang mendukung peningkatan kemampuan membaca, menulis, sains dan berhitung. Dalam kaitan itu, posisi program studi Pendidikan Guru Sekolah Dasar (PGSD) sangat strategis.

Kedudukan program studi PGSD menjadi titik sentral perbaikan proses pembelajaran di SD agar pelaksanaannya sesuai dengan pembelajaran berbasis HOTS. Seperti yang diamanatkan dalam UU No 14/2005, program studi PGSD mempunyai tugas mengasuh mahasiswa agar menjadi pendidik professional dengan tugas utama mendidik, mengajar, membimbing, mengarahkan, melatih, menilai, dan mengevaluasi peserta didik (Pasal1). Ditegaskan pula bahwa mahasiswa PGSD sebagai agen 
pembelajaran berkewajiban untuk meningkatkan mutu pendidikan nasional (Pasal 4). Mengacu pada isi UU No. 14/2005 tersebut, dikatakan dengan sangat jelas bahwa mahasisswa PGSD merupakan komponen yang sangat penting dalam pendidikan, khususnya di SD. Mahasiswa PGSD, menurut merupakan variabel determinan bagi keberhasilan proses pembelajaran di sekolah (Suwandi, 2003a, 2003d, 2004).

Oleh karena itu, perbaikan mutu pembelajaran di SD, sebagai "soko-guru" pendidikan di Indonesia perlu melibatkan mahasiswa PGSD, sebagai calon guru yang diharapkan akan memberi kontribusi besar dalam peningkatan kualitas pendidikan di masa mendatang. Faktor penentu keberhasilan pelaksanaan kegiatan pembelajaran di SD salah satunya adalah Mahasiswa PGSD karena mereka adalah calon guru SD yang perlu menyiapkan kemampuan memadai ketika menjadi guru nantinya. Maka dari itu, mahasiswa PGSD harus memahami kurikulum secara komprehensif mulai dari konsep teori sampai dengan implementasinya di dalam kelas. Namun dalam pelaksanaan di lapangan tidak jarang ditemukan masalah-masalah, dan kegagalan dalam pembelajaran yang disebabkan oleh kekurangpahaman mahasiswa terhadap konsepkonsep pembelajaran.

Dalam kaitan itu, Kemendikbud juga telah menyusun asesmen untuk mengukur kemampuan membaca, menulis, dan berhitung siswa SD, SMP, dan SMA. Asesmen tersebut dinamai AKSI (Asesmen Kompetensi Siswa Indonesia) yang mengukur kompetensi membaca, menulis, dan berhitung para siswa. AKSI menjadi instrumen penting pendidikan di Indonesia yang sejalan dengan beberapa asesmen tingkat dunia, seperti yang dibuat oleh PISA dan TIMSS.

Senada dengan program AKSI, Kemendikbud juga telah menyelenggarakan sejumlah pelatihan bagi guru untuk menyusun soal berbasis HOTS. Guru-guru dari berbagai tingkat sekolah, dari SD sampai dengan SMA, telah diundang untuk mengikuti pelatihan tersebut, yang diselenggarakan di pusat (Jakarta) maupun di daerah. Langkah-langkah yang telah dilakukan tersebut memiliki posisi yang sangat strategis.

Begitu pula pelatihan menyusun soal HOTS, hanya bertujuan agar para guru mampu membuat tes hasil belajar yang tidak hanya mengungkap kompetensi tingkat rendah (C1-C4 dalam klasifikasi S.Bloom), namun juga kompetensi tingkat tinggi (C5-C6). Keduanya belum mencakup perbaikan sistem pembelajaran.

Oleh karena itu kepada para mahasiswa calon guru perlu dibelajarkan cara-cara menyusun rencana, mengembangkan, dan melaksanakan pembelajaran yang berbasis pada kompetensi berpikir siswa tingkat tinggi atau HOTS. Pembelajaran tersebut hendaknya dirancang dan dilaksanakan dengan basis kompetensi AKSI dan HOTS. Selanjutnya, kemampuan mahasiswa tersebut perlu diukur agar dapat diketahui peta persebarannya. Hasil dari pengukuran tersebut dapat dijadikan rujukan, baik oleh perguruan tinggi, pemerintah, maupun lembaga riset dalam menetapkan kebijakan peningkatan mutu pembelajaran dan pengukuran kompetensi sumber daya manusia.

Di SD kelas rendah (kelas 1,2, dan 3), dilaksanakan pembelajaran tematik terpadu, yang di dalamnya mencakup tiga kemampuan dasar, yaitu membaca, menulis, dan berhitung. Oleh karena itu pembelajaran tematik terpadu dikenal sebagai pembelajaran Calistung atau pembelajaran aritmatika-bahasa. Kemampuan membaca dan menulis termasuk kemampuan bahasa; sedangkan kemampuan berhitung termasuk kemampuan aritmatika, yang di dalamnya terdapat kemampuan sains. Dengan demikian, di SD kemampuan membaca, menulis, sains, dan matematika diringkas menjadi kemampuan calistung.

Demikianlah latar belakang praktis dan konseptual penelitian ini. Hasil studi lembaga riset internasional menunjukkan bahwa kemampuan dasar calistung para siswa di Indonesia masih rendah. Meskipun berbagai upaya telah dilakukan oleh pemerintah untuk mengatasi hal tersebut, namun dalam praktiknya 
JURNAL KIPRAH. November 2019; 7 (2): 107-116

ISSN (online): 2580-6947

ISSN (print): 2354-7278

upaya tersebut belumlah komprehensif. Persoalan utamanya adalah bagaimana pembelajaran di sekolah, khususnya SD, dilaksanakan dengan baik dan mendukung peningkatan kompetensi membaca, menulis, sains, dan berhitung. Untuk itu, pembelajaran di SD hendaknya dirancang dan dilaksanakan agar muncul sikap suka membaca dan menulis, serta peningkatan kemampuan sains dan berfikir tingkat tinggi di kalangan para siswa.

Sekaitan dengan hal tersebut, kemampuan para mahasiswa PGSD sebagai calon guru dalam menyusun rancangan dan melaksanakan pembelajaran berbasis AKSI dan HOTS perlu ditingkatkan. Mereka perlu memperoleh pengalaman belajar yang cukup dalam merancang dan melaksanakan pembelajaran berbasis AKSI dan HOTS. Selanjutnya, pada akhir pembelajaran, kemampuan para mahasiswa tersebut perlu diukur agar dapat diketahui kualitasnya. Pengukuran kemampuan mahasiswa itu dipandang ideal bagi sasaran penelitian.

\section{Metode Penelitian}

\section{Desain Penelitian}

Penelitian ini menggunakan desain mix methods, yang menggabungkan desain kuantitatif dan kualitatif tetapi pada tataran yang sederhana. Desain penelitian semacam ini dikenal sebagai Concurrent Mix Methode.

\section{Populasi dan Sampel}

Populasi penelitian ini adalah mahasiswa PGSD. Adapun populasinya adalah mahasiswa semester 6 yang berjumlah 270 orang. Selanjutnya sampel diambil secara bertujuan (purposive sampling), sebanyak 154 orang. Mereka adalah bagian dari populasi yang dipilih berdasarkan kriteria telah mengikuti dan lulus seluruh matakuliah pokok pembelajaran.

\section{Instrumen Penelitian}

Instrumen penelitian ini adalah Instrumen lembar observasi digunakan untuk menjaring data karakteristik mahasiswa dan pelaksanaan kegiatan praktik kelompok (penyusunan RPP dan simulasi pembelajaran). Instrumen angket digunakan untuk menjaring data pemahaman awal mahasiswa terhadap konsep pembelajaran. Adapun instrumen tes digunakan untuk menilai hasil belajar dan menilai pelaksanaan simulasi.

Dalam kaitan dengan RPP, penilaian juga dilakukan dengan menganalisis fragmen RPP berdasarkan kisi-kisi yang telah disusun sebelumnya. Kisi-kisi disusun berdasarkan teori RPP berbasis HOTS.

\section{Teknik Pengumpulan Data Penelitian}

Dalam penelitian ini, data dikumpulkan menggunakan empat metode, yaitu observasi, angket, analisis fragmen/komponen, dan tes. Angket digunakan untuk menjaring data pemahaman pada tingkat teoretis. Analisis fragmen digunakan untuk menjaring data pemahaman subjek dalam menyusun RPP. Observasi digunakan untuk menjaring data pemahaman subjek terhadap praktik mengajar. Tes digunakan untuk menjaring data keterampilan melaksanakan pembelajaran, yang terdiri atas keterampilan mengajar dan keterampilan menilai.

Untuk menilai pemahaman subjek pada aspek penyusunan RPP dilakukan analisis komponen RPP. Analisis komponen dilakukan terhadap 4 komponen, yakni pengintegrasian PPK, Literasi, Kemampuan 4C, dan kemampuan berfikir HOTS dalam seluruh kegiatan pembelajaran yang dirancang dalam RPP. Aspek-aspek standar RPP yang ada dalam kurikulum, yakni Identitas Mata Pelajaran/Tema, Perumusan Indikator, Perumusan Materi Ajar, Sumber Belajar, Media Pembelajaran tidak dianalisis. Indikator penilaian RPP digambarkan pada tabel berikut.

Tabel 1. Indikator Penilaian RPP

\begin{tabular}{|c|c|c|c|c|c|c|c|c|c|}
\hline \multirow[t]{2}{*}{$\begin{array}{c}\text { Fragmen RPP } \\
\text { yang Dinilai }\end{array}$} & \multicolumn{2}{|c|}{$\begin{array}{c}\text { SR } \\
\text { (Skor= } \\
>70)\end{array}$} & \multicolumn{2}{|c|}{$\begin{array}{c}\text { TS } \\
\text { (Skor } \\
71-75 \text { ) } \\
\end{array}$} & \multicolumn{2}{|c|}{$\begin{array}{c}\text { CT } \\
\text { (Skor } \\
76-80) \\
\end{array}$} & \multicolumn{2}{|c|}{$\begin{array}{c}\text { ST } \\
\text { (Skor } \\
\Rightarrow 81)\end{array}$} & \multirow[t]{2}{*}{$\sum$} \\
\hline & $\sum$ & $\%$ & $\sum$ & $\%$ & $\sum$ & $\%$ & $\sum$ & $\%$ & \\
\hline \multicolumn{10}{|l|}{ PPK } \\
\hline \multicolumn{10}{|l|}{ Literasi } \\
\hline \multicolumn{10}{|l|}{ Kemampuan 4C } \\
\hline \multicolumn{10}{|l|}{ Berfikir HOTS } \\
\hline$\%$ Rata- & & & & & & & & & \\
\hline
\end{tabular}

Data tentang keterampilan mengajar dikumpulkan melalui observasi dan tes. Pengamatan pelaksanaan pembelajaran kemudian dicatat dalam lembar observasi seperti 
terlihat pada tabel berikut.

Tabel 2. Kisi-Kisi Observasi Kemampuan

Melaksanakan Pembelajaran HOTS

\begin{tabular}{|c|c|c|c|c|c|c|c|c|c|}
\hline \multirow[t]{2}{*}{ Aspek yang Diamati } & \multicolumn{2}{|c|}{$\begin{array}{c}\text { SR } \\
\text { (Skor } \\
=>70)\end{array}$} & \multicolumn{2}{|c|}{$\begin{array}{c}\text { TS } \\
\text { (Skor } \\
71- \\
75 \text { ) } \\
\end{array}$} & \multicolumn{2}{|c|}{$\begin{array}{c}\text { CT } \\
\text { (Skor } \\
76- \\
80 \text { ) } \\
\end{array}$} & \multicolumn{2}{|c|}{$\begin{array}{c}\text { ST } \\
\text { (Skor } \\
\Rightarrow> \\
81 \text { ) } \\
\end{array}$} & \multirow[t]{2}{*}{$\Sigma$} \\
\hline & $\sum$ & $\%$ & $\sum$ & $\%$ & $\sum$ & $\%$ & $\sum$ & $\%$ & \\
\hline $\begin{array}{ll}\begin{array}{l}\text { Pendekatan } \\
\text { dipilih }\end{array} & \text { yang } \\
\end{array}$ & & & & & & & & & \\
\hline $\begin{array}{l}\text { Kemampuan } \\
\text { mengelola } \\
\text { Pembelajaran Aktif }\end{array}$ & & & & & & & & & \\
\hline $\begin{array}{ll}\begin{array}{l}\text { Pemilihan } \\
\text { pembelajaran }\end{array} & \text { media } \\
\end{array}$ & & & & & & & & & \\
\hline $\begin{array}{l}\text { Pelaksanaan } \\
\text { penilaian }\end{array}$ & & & & & & & & & \\
\hline$\%$ Rata-r & & & & & & & & & \\
\hline
\end{tabular}

\section{Teknik Analisis Data Penelitian}

Pada tahap pertama dilakukan analisis kuantitatif dengan menghitung skor dan persentase berdasarkan data yang diperoleh melalui angket dan tes. Selanjutnya dilakukan analisis data kualitatif melalui pemahaman atau interpretasi terhadap hasil observasi dan analisis komponen. Analisis interpretasi tersebut dilakukan untuk melengkapi deskripsi data kuantitatif dengan tujuan membuktikan, memperdalam, dan memperluas pemahaman terhadap data. Untuk itu digunakan uraian atau deskripsi sistematis menggunakan kata-kata.

Penelitian ini mencoba untuk mendapatkan pemahaman yang lebih baik mengenai kompleksitas yang terjadi dalam proses belajar-mengajar calistung berbasis HOTS. Fenomena tersebut bersifat alamiah, karena itu harus didekati secara alamiah pula. Pendekatan kualitatif dipandang sesuai karena pendekatan tersebut mengkaji fenomena pada ranah alamiah.

Pada sisi lain, penelitian ini menghasilkan dan mengolah data yang sifatnya deskriptif kuantitatif, yang diperoleh melalui angket dan tes. Oleh karena itu, diperlukan pengolahan data statistik sedernaha agar memperoleh deskripsi berupa skor dan persentase. Maka dari itu, penggunaan desain mix method relevan digunakan dalam penelitian ini. Akan tetapi, secara umum penelitian ini lebih mementingkan pendekatan kualitatif daripada kuantitatif dalam mengambil simpulan terhadap fenomena yang diamati.

\section{Penelitian}

Untuk memvalidasi data digunakan teknik triangulasi. Penelitian ini melakukan triangulasi dengan menggunakan beberapa metode. Teknik triangulasi pertama adalah triangulasi sumber data, yaitu menggali kebenaran informasi melalui berbagai metode dan sumber perolehan data. Selain melalui observasi, peneliti juga melakukan pengumpulan data menggunakan angket, analisis komponen, dan tes. Di samping itu, dalam penelitian ini juga dilakukan triangulasi teori. Dalam triangulasi ini rumusan informasi atau thesis statement dibandingkan dengan perspektif teori yang televan untuk menghindari bias individual peneliti atas simpulan yang dibuat. Triangulasi teori juga digunakan untuk meningkatkan kedalaman pemahaman peneliti terhadap hasil analisis data yang telah diperoleh. Melalui berbagai perspektif teoretis diharapkan diperoleh hasil yang mendekati kebenaran.

\section{Hasil dan Pembahasan}

Kemampuan Mahasiswa PGSD dalam Merancang dan Melaksanakan Pembelajaran Berbasis HOTS di Sekolah Dasar

Berdasarkan temuan di lapangan, kemampuan mahasiswa PGSD Universitas Jambi dalam merancang dan melaksanakan pembelajaran berbasis High Order Thinking Skills (HOTS) di SD terbagi menjadi 4 kategori, yaitu sangat tinggi (ST), cukup tinggi (CT), tinggi sedang (TS), dan sangat rendah (SR). Temuan tersebut diperoleh melalui hasil tes dan unjuk kerja (UKIN) 154 mahasiswa semester 6, sebagai responden. Hasil tes dan unjuk kerja berdasarkan kategori di atas dapat dilihat pada Tabel 3 berikut ini.

Tabel 3. Hasil Kemampuan Berpikir Kritis Siswa

\begin{tabular}{|l|l|c|c|c|c|l|}
\hline \multirow{2}{*}{ No. } & \multirow{2}{*}{ Kategori } & \multicolumn{2}{|c|}{$\begin{array}{c}\text { Jumlah } \\
\text { Responden }\end{array}$} & \multicolumn{2}{c|}{ Persentase Keberhasilan (\%) } \\
\cline { 3 - 7 } & Tes & UKIN & Tes & UKIN & Rata-rata \\
\hline 1. & SR (Skor => 70) & 72 & 81 & 46,75 & 52,59 & 49,67 \\
\hline 2. & $\begin{array}{l}\text { TS (Skor 71 - } \\
75)\end{array}$ & 47 & 33 & 30,51 & 21,42 & 25,96 \\
\hline 3. & $\begin{array}{l}\text { CT (Skor 76 - } \\
80)\end{array}$ & 21 & 23 & 13,63 & 14,93 & 14,28 \\
\hline
\end{tabular}


JURNAL KIPRAH. November 2019; 7 (2): 107-116

ISSN (online): 2580-6947

ISSN (print): 2354-7278

\begin{tabular}{|l|c|c|c|c|c|l|}
\hline 4. & ST $($ Skor $=>81)$ & 14 & 17 & 9,09 & 11,03 & 10,06 \\
\hline Jumlah & 154 & 154 & 99,98 & 99,97 & \\
\hline
\end{tabular}

Pada Tabel 3 tersebut terlihat, bahwa mahasiswa PGSD yang memiliki kemampuan ST hanya $10,06 \%$, CT $=14,28 \%$, TS $=25,96$, dan $\mathrm{SR}=49,67 \%$. Dengan pedoman angka KKM $($ Kriteria Ketuntasan Minimal $)=70 \%$, maka hanya sekitar 50,33\% mahasiswa yang dapat dinyatakan Tuntas, dan sisanya yakni sebesar 49,67\% Tidak Tuntas. Hasil ini cukup memprihatinkan karena mahasiswa semester 6 telah memperoleh lebih dari $80 \%$ mata kuliah yang berkaitan dengan metodologi pembelajaran. Disamping itu, mereka akan mengikuti Pengalaman Lapangan Persekolahan (PLP) pada semester 7. Artinya, mereka sudah harus memiliki kesiapan dan kemampuan mengajar di dalam kelas.

Jika dilihat dari aspek-aspek yang dinilai dalam mempersiapkan dan melaksanakan pembelajaran, maka hasil yang diperoleh pada penelitian ini berdasarkan data yang terkumpul juga cukup memprihatinkan. Mahasiswa tampak lemah pada hampir semua aspek yang dinilai. Data selengkapnya dapat dilihat pada table 4 berikut.

Tabel 4. Skor yang Diperoleh Responden Per Aspek Penilaian

\begin{tabular}{|c|c|c|c|c|c|c|c|}
\hline \multirow{2}{*}{$\begin{array}{l}\mathbf{N} \\
\mathbf{o}\end{array}$} & \multirow{2}{*}{$\begin{array}{l}\text { Aspek yang } \\
\text { Dinilai }\end{array}$} & \multirow{2}{*}{$\begin{array}{c}\text { Instru } \\
\text { men }\end{array}$} & \multicolumn{4}{|c|}{$\begin{array}{l}\text { Jumlah } \\
\text { Menurut Skor Per Asponden }\end{array}$} & \multirow{2}{*}{$\underset{\text { ah }}{\text { Juml }}$} \\
\hline & & & $\begin{array}{l}S \\
T\end{array}$ & CT & TS & SR & \\
\hline 1 & $\begin{array}{l}\text { Pengetahuan } \\
\text { Dasar }\end{array}$ & Tes & 24 & 31 & 40 & 59 & 154 \\
\hline 2 & $\begin{array}{l}\text { Kemampuan } \\
\text { Menyusun RPP }\end{array}$ & UKIN & 30 & 32 & 41 & 51 & 154 \\
\hline 3 & $\begin{array}{l}\text { Kemampuan } \\
\text { Mengembangka } \\
\text { n Media } \\
\text { Pembelajaran } \\
\end{array}$ & UKIN & 45 & 61 & 36 & 12 & 154 \\
\hline 4 & $\begin{array}{l}\text { Kemampuan } \\
\text { Melaksanakan } \\
\text { Pembelajaran }\end{array}$ & UKIN & 12 & 31 & 59 & 52 & 154 \\
\hline 5 & $\begin{array}{l}\text { Kemampuan } \\
\text { Merancang } \\
\text { Instrumen } \\
\text { Penilaian } \\
\end{array}$ & UKIN & 9 & 17 & 68 & 60 & 154 \\
\hline 6 & $\begin{array}{l}\text { Kemampuan } \\
\text { Melaksanakan } \\
\text { Penilaian }\end{array}$ & UKIN & 17 & 36 & 23 & 78 & 154 \\
\hline
\end{tabular}

Data Tabel 4 di atas menunjukkan, kemampuan mahasiswa rendah hampir pada semua aspek yang dinilai dalam merancang dan melaksanakan pembelajaran berbasis HOTS. Jumlah mahasiswa yang berada pada skor SR (tidak mencapai KKM) adalah 52\%. Artinya, hanya $48 \%$ mahasiswa yang telah mencapai KKM. Hanya pada aspek mengembangkan media saja yang mencapai skor paling tinggi, yakni 45 orang mahasiswa $(29,22 \%)$. Sementara, pada aspek lain hampir semua mahasiswa responden bernilai rendah dalam merancang dan melaksanakan pembelajaran berbasis HOTS.

\section{Kemampuan Mahasiswa dalam Pengetahuan} Dasar Pembelajaran HOTS

Tabel 5. Hasil Tes Pengetahuan Dasar Mahasiswa Terhadap Pembelajaran HOTS

\begin{tabular}{|c|c|c|c|c|}
\hline $\begin{array}{l}\mathbf{N} \\
\mathbf{o}\end{array}$ & $\begin{array}{c}\text { Aspek } \\
\text { Pengetahuan } \\
\text { yang Dinilai }\end{array}$ & Sub-Aspek Pengetahuan & $\begin{array}{l}\text { Skor } \\
\text { Rata- } \\
\text { Rata }\end{array}$ & $\begin{array}{l}\text { Jumlah } \\
\text { Butir } \\
\text { Soal }\end{array}$ \\
\hline \multirow[t]{3}{*}{1.} & \multirow[t]{3}{*}{ Menganalisis } & $\begin{array}{l}\text { a. Menganalis informasi } \\
\text { yang masuk dan } \\
\text { membagi-bagi atau } \\
\text { menstrukturkan } \\
\text { informasi ke dalam } \\
\text { bagian yang lebih } \\
\text { kecil untuk } \\
\text { mengenali pola atau } \\
\text { hubungannya. }\end{array}$ & \multirow[t]{3}{*}{$\begin{array}{c}76,6 \\
9\end{array}$} & \multirow[t]{3}{*}{20} \\
\hline & & $\begin{array}{l}\text { b. Mengidetifikasi/ } \\
\text { merumuskan } \\
\text { pertanyaan. }\end{array}$ & & \\
\hline & & $\begin{array}{l}\text { a. Mampu mengenali } \\
\text { serta membedakan } \\
\text { faktor penyebab dan } \\
\text { akibat dari sebuah } \\
\text { permasalahan. }\end{array}$ & & \\
\hline \multirow[t]{3}{*}{2} & \multirow[t]{3}{*}{ Mengevaluasi } & 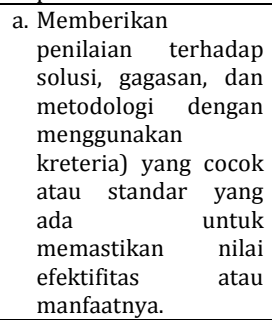 & \multirow[t]{3}{*}{$\begin{array}{c}73,7 \\
4\end{array}$} & \multirow[t]{3}{*}{20} \\
\hline & & $\begin{array}{l}\text { b. Membuat hipotesis, } \\
\text { mengkritik, dan } \\
\text { melakukan } \\
\text { pengujian. }\end{array}$ & & \\
\hline & & $\begin{array}{lr}\text { c. Menerima atau } \\
\text { menolak suatu } \\
\text { pernyataan } \\
\text { berdasarkan } \\
\text { yang telah ditetapkan }\end{array}$ & & \\
\hline \multirow[t]{3}{*}{3.} & \multirow[t]{3}{*}{$\begin{array}{l}\text { Mengkreasi } \\
\text { atau Mencipta }\end{array}$} & $\begin{array}{lr}\text { a. Membuat } & \\
\text { generalisasi } & \text { suatu ide } \\
\text { atau cara } & \text { pandang } \\
\text { terhadap } & \text { suatu } \\
\text { masalah; } & \end{array}$ & \multirow[t]{3}{*}{$\begin{array}{c}47,7 \\
6\end{array}$} & \multirow[t]{3}{*}{20} \\
\hline & & $\begin{array}{l}\text { b. Merancang satu cara } \\
\text { untuk menyelesaikan } \\
\text { masalah; }\end{array}$ & & \\
\hline & & $\begin{array}{l}\text { c. Mengorganisasikan } \\
\text { unsur-unsur atau } \\
\text { bagian-bagian } \\
\text { menjadi struktur } \\
\text { baru yang belum ada } \\
\text { sebelumnya. }\end{array}$ & & \\
\hline
\end{tabular}

Dari data pada Tabel 5 di atas diketahui bahwa pada aspek pengetahuan tentang Menganalisis, mahasiswa/ responden mampu memperoleh skor pengetahuan yang cukup 
tinggi, yakni rata-rata 76,69. Pada aspek Mengevaluasi, peroleh nilai mahasiswa lebih rendah, yakni rata-rata 73,74 . Sementara pada aspek pengetahuan tentang Mengkreasi atau Mencipta, nilai yang diperoleh mahasiswa/responden sangat rendah, yakni 47,76. Dalam kategorisasi pengetahuan menurut Bloom, Menganalisis berada pada level 4, Mengevaluasi berada pada level 5, dan Mengkreasi atau Mencipta berada pada level 6 . Berdasarkan data di atas, maka dapat disimpulkan bahwa pengetahuan mahasiswa pada level 6 (level tertinggi) masih rendah. Hal inilah yang dapat diduga menyebabkan kemampuan mahasiswa dalam merancang dan melaksanakan pembelajaran berbasis HOTS masih rendah. Hal itu dipicu oleh rendahnya pengetahuan mereka tentang konsepsi pembelajaran HOTS itu sendiri.

Hasil analisis data sebagaimana tercantum pada tabel 5 di atas mengarahkan peneliti untuk menganalisisnya lebih dalam berdasarkan indikator aspek kemampuan berpikir mahasiswa. Hasilnya dapat disajikan pada tabel berikut.

Tabel 6. Kemampuan Mahasiswa Pada Aspek Berpikir Kritis, Kreatif, dan Pemecahan Masalah

\begin{tabular}{|c|c|c|c|c|c|}
\hline No & $\begin{array}{c}\text { Aspek } \\
\text { Kognitif }\end{array}$ & & $\begin{array}{c}\text { Sub-Aspek yang } \\
\text { Dinilai }\end{array}$ & $\begin{array}{c}\text { Skor } \\
\text { Rata- } \\
\text { rata } \\
\text { Per } \\
\text { Sub- } \\
\text { Aspek }\end{array}$ & $\begin{array}{c}\text { Skor } \\
\text { Rata- } \\
\text { rata } \\
\text { Per } \\
\text { Aspek }\end{array}$ \\
\hline \multirow[t]{6}{*}{1.} & \multirow[t]{6}{*}{$\begin{array}{l}\text { Berpikir } \\
\text { Kritis }\end{array}$} & 1) & $\begin{array}{l}\text { mengajukan } \\
\text { pertanyaan }\end{array}$ & 81,10 & \multirow[t]{6}{*}{75.69} \\
\hline & & & $\begin{array}{l}\text { merevisi konsep } \\
\text { yang salah }\end{array}$ & 78,75 & \\
\hline & & & $\begin{array}{l}\text { merencanakan } \\
\text { strategi }\end{array}$ & 77,79 & \\
\hline & & & $\begin{array}{l}\text { mengevaluasi } \\
\text { keputusan }\end{array}$ & 79,01 & \\
\hline & & & $\begin{array}{ll}\text { mengkritik suatu } \\
\text { pernyataan }\end{array}$ & 67,74 & \\
\hline & & & $\begin{array}{l}\text { mengevaluasi } \\
\text { keputusan. }\end{array}$ & 69,78 & \\
\hline \multirow[t]{7}{*}{2.} & \multirow[t]{7}{*}{$\begin{array}{l}\text { Berpikir } \\
\text { Kreatif }\end{array}$} & & $\begin{array}{l}\text { memformulasikan } \\
\text { persamaan }\end{array}$ & 78,77 & \multirow[t]{7}{*}{72.35} \\
\hline & & & $\begin{array}{l}\text { membangun } \\
\text { keterkaitan } \\
\text { antarkonsep }\end{array}$ & 72,72 & \\
\hline & & & $\begin{array}{l}\text { mengusulkan ide } \\
\text { baru }\end{array}$ & 67,72 & \\
\hline & & & $\begin{array}{l}\text { menyusun } \\
\text { hubungan konsep- } \\
\text { konsep dalam } \\
\text { bentuk skema }\end{array}$ & 60,01 & \\
\hline & & & $\begin{array}{l}\text { menggambarkan } \\
\text { ide }\end{array}$ & 67,02 & \\
\hline & & 12) & $\begin{array}{l}\text { berani } \\
\text { bereksperimen }\end{array}$ & 65,62 & \\
\hline & & 13) & mengorganisasi & 74,75 & \\
\hline
\end{tabular}

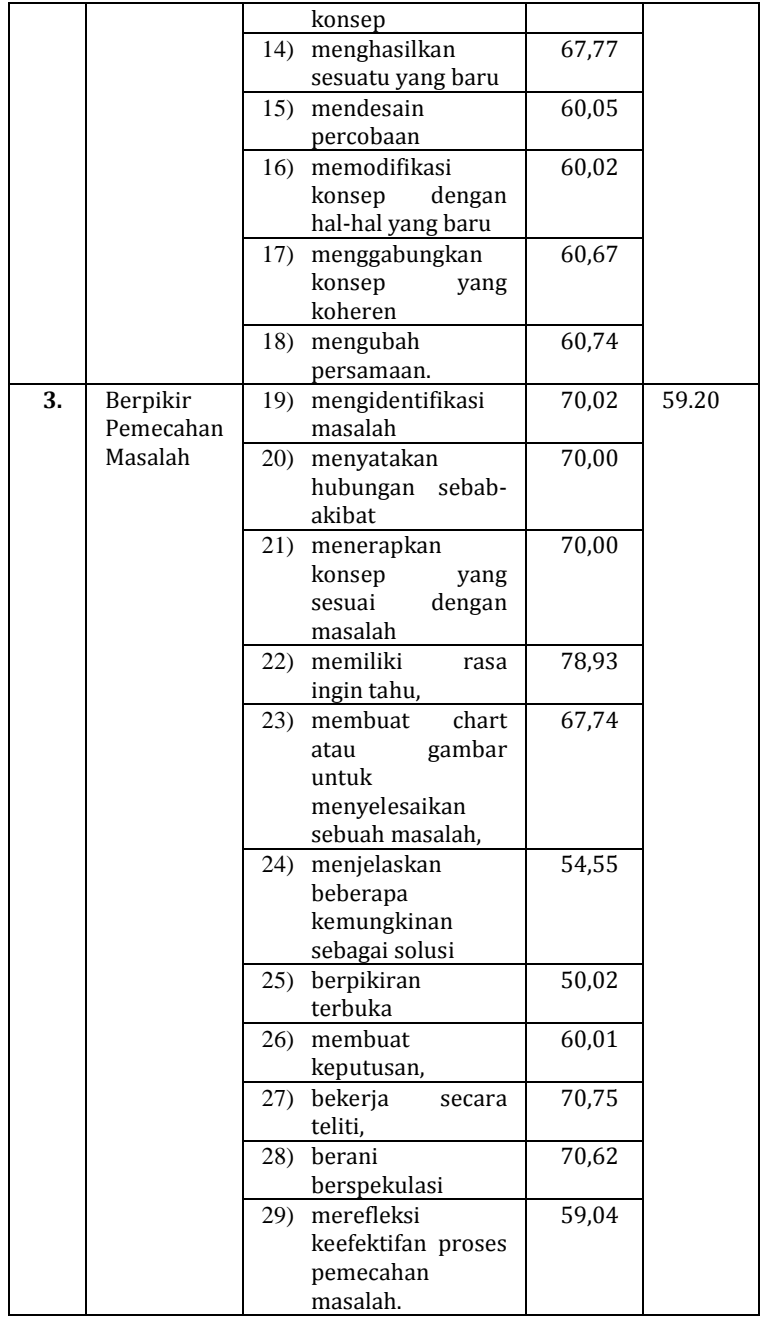

Berdasarkan data Tabel 6 di atas diketahui bahwa pada aspek Berpikir Kritis responden memperoleh nilai rata-rata 75,69. Pada aspek Berpikir Kreatif responden memperoleh nilai rata-rata 72.35. Pada aspek Berpikir Pemecahan Masalah, responden memperoleh nilai rata-rata 59.20. Dengan demikian, pada ketiga aspek tersebut kemampuan mahasiswa secara berturutturut adalah 75,69 (TS), 72.35 (TS), dan 59.20 (SR). Dari data tersebut dapat disimpulkan bahwa pengetahuan dasar mahasiswa tentang konsep pembejaran HOTS sangat rendah pada aspek Berpikir Pemecahan Masalah. Hasil tersebut dapat digambarkan dalam bentuk diagram sebagai berikut. 
JURNAL KIPRAH. November 2019; 7 (2): 107-116

ISSN (online): 2580-6947

ISSN (print): 2354-7278

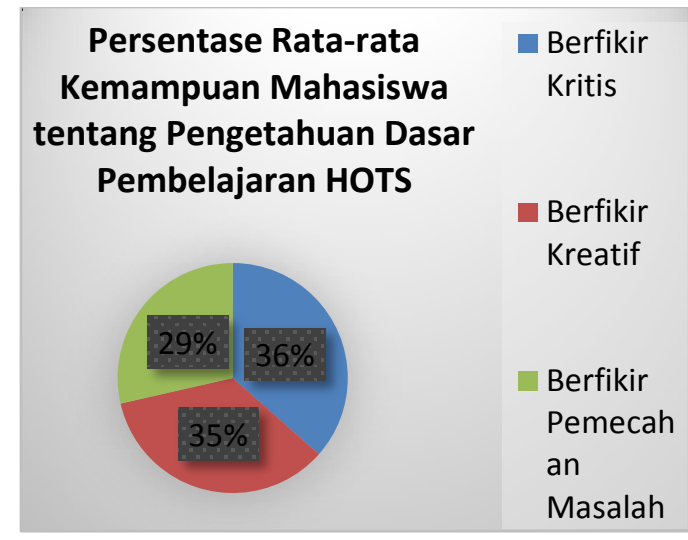

Bagan 1. Persentase Kemampuan Mahasiswa tentang Pengetahuan Dasar Pembelajaran HOTS

\section{Kemampuan Mahasiswa dalam Penyusunan} RPP Pembelajaran HOTS

Berdasarkan analisis data diketahui bahwa kemampuan mahasiswa responden dalam menyusun RPP Pembelajaran HOTS masih jauh dari harapan. Data menunjukkan bahwa rata-rata kemampuan mahasiswa untuk tiap aspek yang dinilai, yakni pengintegrasian PPK, Literasi, Kemampuan 4C, dan kemampuan berfikir HOTS adalah sebagai berikut.

Tabel 7. Kemampuan Mahasiswa dalam Menyusun RPP Pembelajaran HOTS

\begin{tabular}{|c|c|c|c|c|c|c|c|c|c|}
\hline \multirow{2}{*}{$\begin{array}{c}\text { Fragme } \\
\text { n RPP } \\
\text { yang } \\
\text { Dinilai }\end{array}$} & \multicolumn{2}{|c|}{$\begin{array}{c}\mathrm{SR} \\
\text { (Skor }=>70)\end{array}$} & \multicolumn{2}{|c|}{$\begin{array}{c}\text { TS } \\
\text { (Skor 71-75) } \\
\end{array}$} & \multicolumn{2}{|c|}{$\begin{array}{c}\text { CT } \\
\text { (Skor 76- } \\
80 \text { ) } \\
\end{array}$} & \multicolumn{2}{|c|}{$\begin{array}{c}\text { ST } \\
\text { (Skor }=> \\
81 \text { ) }\end{array}$} & \multirow{2}{*}{$\Sigma$} \\
\hline & $\Sigma$ & $\%$ & $\Sigma$ & $\%$ & $\Sigma$ & $\%$ & $\Sigma$ & $\%$ & \\
\hline PPK & 73 & 47.40 & 61 & 39.61 & 12 & $\begin{array}{r}7.7 \\
9\end{array}$ & 8 & $\begin{array}{r}5.1 \\
9\end{array}$ & 154 \\
\hline Literasi & 60 & 38.96 & 57 & 37.01 & 25 & $\begin{array}{l}16 . \\
23 \\
\end{array}$ & 12 & $\begin{array}{r}7.7 \\
9 \\
\end{array}$ & 154 \\
\hline $\begin{array}{l}\text { Kemam } \\
\text { puan 4C }\end{array}$ & 62 & 40.26 & 62 & 40.26 & 18 & $\begin{array}{c}11 . \\
69 \\
\end{array}$ & 12 & $\begin{array}{r}7.7 \\
9 \\
\end{array}$ & 154 \\
\hline $\begin{array}{l}\text { Berfikir } \\
\text { HOTS }\end{array}$ & 54 & 35.06 & 67 & 43.51 & 22 & $\begin{array}{l}14 . \\
29 \\
\end{array}$ & 11 & $\begin{array}{r}7.1 \\
4 \\
\end{array}$ & 154 \\
\hline \multicolumn{2}{|c|}{$\%$ Rata-rata } & 40.42 & & 40.10 & & 12.50 & & 6.98 & $100 \%$ \\
\hline
\end{tabular}

Berdasarkan data Tabel 7 di atas diketahui bahwa kemampuan mahasiswa dalam menyusun RPP untuk pembelajaran HOTS adalah sebagai berikut. Dari keseluruhan fragmen yang dinilai, kemampuan mahasiswa secara berturut-turut adalah $6.98 \%$ (TS), $12.50 \%$ (CT), $40.10 \%$ (TS), dan $40.42 \%$ (SR). Jika menggunakan ukuran KKM 70, maka 40,42\% mahasiswa dinyatakan Tidak Memenuhi KKM, dan yang memenuhi KKM hanya 59,68\%. Hampir separoh mahasiswa tidak lulus.

Angka terendah diperoleh mahasiswa pada aspek pengintegrasian PPK. Dari 154 mahasiswa, 73 orang $(47,40 \%)$ memperoleh nilai sangat rendah. Pada fragmen literasi 60 orang mahasiswa $(38,96 \%)$ memperoleh nilai sangat rendah. Pada fragmen kemampuan 4C, 62 orang mahasiswa $(40,26 \%)$ memperoleh nilai sangat rendah. Pada fragmen berfikir tingkat tinggi, 54 orang mahasiswa $(40,26 \%)$ memperoleh nilai sangat rendah.

\section{Kemampuan Mahasiswa dalam Melaksanakan dan Menilai Pembelajaran HOTS}

Adapun aspek yang diamati dalam pelaksanaan pembelajaran HOTS adalah sebagai berikut.

Table 8. Kemampuan Mahasiswa dalam Melaksanakan Pembelajaran HOTS

\begin{tabular}{|c|c|c|c|c|c|c|c|c|c|}
\hline \multirow{2}{*}{$\begin{array}{c}\text { Aspek } \\
\text { yang } \\
\text { Diamati }\end{array}$} & \multicolumn{2}{|c|}{$\begin{array}{c}\mathrm{SR} \\
(\text { Skor }=>70)\end{array}$} & \multicolumn{2}{|c|}{$\begin{array}{c}\text { TS } \\
\text { (Skor 71- } \\
75 \text { ) } \\
\end{array}$} & \multicolumn{2}{|c|}{$\begin{array}{c}\text { CT } \\
\text { (Skor 76- } \\
80) \\
\end{array}$} & \multicolumn{2}{|c|}{$\begin{array}{c}\text { ST } \\
(\text { Skor } \Rightarrow> \\
81)\end{array}$} & \multirow[t]{2}{*}{$\Sigma$} \\
\hline & $\Sigma$ & $\%$ & $\Sigma$ & $\%$ & $\Sigma$ & $\%$ & $\Sigma$ & $\%$ & \\
\hline $\begin{array}{l}\text { Pendekata } \\
\mathrm{n} \text { yang } \\
\text { dipilih }\end{array}$ & 76 & 49.35 & 32 & 20.78 & 22 & 14.29 & 24 & $\begin{array}{l}15.5 \\
8\end{array}$ & 154 \\
\hline $\begin{array}{l}\text { Kemampu } \\
\text { an } \\
\text { mengelola } \\
\text { Pembelaja } \\
\text { ran Aktif }\end{array}$ & 71 & 46.10 & 43 & 27.92 & 34 & 22.08 & 6 & 3.90 & 154 \\
\hline $\begin{array}{l}\text { Pemilihan } \\
\text { media } \\
\text { pembelaja } \\
\text { ran }\end{array}$ & 76 & 49.35 & 34 & 22.08 & 27 & 17.53 & 17 & $\begin{array}{l}11.0 \\
4\end{array}$ & 154 \\
\hline $\begin{array}{l}\text { Pelaksana } \\
\text { an } \\
\text { penilaian }\end{array}$ & 79 & 51.30 & 18 & 11.69 & 23 & 14.94 & 34 & $\begin{array}{l}22.0 \\
8.0\end{array}$ & 154 \\
\hline \multicolumn{2}{|c|}{$\%$ Rata-rata } & 49,03 & & 20.62 & & 17.21 & & 13.15 & 1000 \\
\hline
\end{tabular}

kemampuan mahasiswa dalam melaksanakan pembelajaran berbasis HOTS juga masih belum memuaskan. Lebih dari 49\% mahasiswa belum menguasai pelaksanaan pembelajaran HOTS. Aspek yang paling rendah pencapaiannya adalah pelaksanaan penilaian, yakni 79 mahasiswa $(51,30 \%)$ belum menggunakan penilaian berbasis HOTS. Namun, yang cukup menggembirakan, dari 154 mahasiswa, 34 diantaranya $(22,08 \%)$ memperoleh nilai Sangat Tinggi (ST).

\section{Pembahasan}

Kaitan antara Hasil Penelitian dan Tinjauan Pustaka

Riset PISA dan TIMS, tentang kemampuan menulis, membaca, dan sains mendudukkan Indonesia pada posisi peringkat 10 terbawah dunia (Kemendikbud, 2018). Pemeringkatan itu mendudukkan Indonesia pada kategori "Rendah" (Kuntarto, 2016). Peringkat Indonesia yang rendah tersebut menunjukkan bahwa proses pembelajaran membaca, menulis, 
sains, dan matematika, yang di sekolah-sekolah di Indonesia belum sesuai dengan harapan semua pihak. Pernyataan ini erat kaitannya dengan hasil penelitian ini.

Berdasarkan analisis data, kemampuan mahasiswa dalam merencanakan dan melaksanakan pembelajaran berbasis HOTS masih rendah. Hanya sekitar $49 \%$ yang telah menguasai. Sisanya, lebih dari 50\% belum menguasai. Hasil penelitian ini perlu dicermati oleh semua pihak jika ingin pembelajaran di Indonesia berhasil seperti di manca negara. Kualitas pendidikan di Indonesia tidak boleh hanya dibebankan kepada guru di sekolah-sekolah (TK/PAUD, SD/MI, SMP/MTs, SMA/SMK/MA) semata tetapi juga kepada dosen LPTK dan perguruan tinggi. Kurikulum pendidikan tinggi, utamanya di LPTK hendaknya sejalan dengan Kurikulum di tingkat sekolah. Sinergitas antara lembaga pendidikan tinggi dan sekolah juga perlu teruis ditingkatkan. Penyusunan kurikulum di PT, misalnya, hendaknya melibatkan stake holder di sekolah

\section{Kesimpulan}

Simpulan berdasarkan hasil penelitian yaitu mayoritas mahasiswa belum menunjukkan kemampuan yang baik dalam merencanakan dan melaksanakan pembelajaran HOTS di SD. Berdasarkan simpulan tersebut, saran bagi LPTK, agar mengembangkan perkuliahan yang berorientasi HOTS, agar mahasiswa dapat menerapkan dalam pembelajaran di sekolah.

Penelitian ini mencakup pada aspek-aspek dan ranah yang terbatas. Oleh karena itu, simpulan atas penelitian ini juga masih terbatas implikasinya. Mengingat pentingnya topik penelitian ini, perlu dilakukan penelitian lanjutan dalam lingkup dan cakupan yang lebih luas, baik variabel maupun ranah jangkauan subjeknya.

Kelemahan yang paling mendasar dari penelitian ini adalah terbatasnya waktu penelitian dan responden yang berkontribusi. Berdasarkan hasil penelitian ini perlu disampaikan rekomendasi sebagai berikut:

a. Para mahasiswa calon guru SD perlu dikenalkan dengan pembelajaran berbasis HOTS;

b. Rendahnya kualitas siswa di Indonesia merupakan akibat langsung dari rendahnya kualitas guru. Oleh karena itu kebijakan tentang mutu guru dan calon guru SD perlu menjadi perhatian serius pemerintah, dengan mengevaluasi guru-guru yang telah memperoleh tunjangan fungsional (tunjangan sertifikasi guru) dan menyiapkan calon guru yang mampu menjawab tantangan perubahan zaman di era abad 21.

\section{Ucapan Terimakasih}

Artikel ini merupakan publikasi hasil penelitian dengan skema Penelitian Dosen Pemula Tahun 2019 menggunakan dana yang bersumber dari Fakultas Keguruan dan Ilmu Pendidikan Universitas Jambi. Oleh karena itu penulis mengucapkan terimakasih kepada FKIP Universitas Jambi atas dukungan pendanaannya demi kesuksesan penelitian ini. Selanjutnya ucapan terimakasih kepada pengelola jurnal KIPRAH karena telah membantu publikasi artikel ini.

\section{Referensi}

Anderson, L. W., \& Krathwohl, D. R. (2001). A Taxonomy for Learning, Teaching and Assessing: A Revision of Bloom's Taxonomy of Educational Objectives: Complete Edition. New York: Longman.

Anderson, L W. (2010). Pembelajaran, Pengajaran, dan Asesmen, Yogyakarta: Pustaka Pelajar.

Andriyani \& Kuntarto, E., (2017). "Etnomatematika: Model Baru dalam Pembelajaran". Jurnal Gantang Vol II No. 2: p. 133-144.

Barrat, C., (2014). Higher Order Thinking And Assessment. International Seminar on current issues in Primary Education: Prodi PGSD Universitas Muhammadiyah Makasar. 
JURNAL KIPRAH. November 2019; 7 (2): 107-116

ISSN (online): 2580-6947

ISSN (print): 2354-7278

Bogdan, R. and Taylor, S.J. (1975). Introduction to Qualitative Research Method. New York : John Willey and Sons.

Bogdan, R. C \& Biklen, S. K. (2003). Qualitative Research for Education: An Introduction to Theories and Methods (4th ed.). New York: Pearson Education Group.

Costa, A. L. (1985). Developing Minds : A Resource Book for Teaching Thinking. ASCD. West Street Alexandria, Virginia.

Creswell, J. W. (2003). Research Design Qualitative, Quantitative and Mixed Methods Approaches Second Edition. Sage Publications. New Delhi.

Eggen, P, Kauchak. 2012. Strategi dan Model Pembelajaran. Jakarta: PT. Indeks.

Eprillia, UH \& Prasetyarini, A., (2012). "Implementasi Metode Pembelajaran Calistung Permulaan Bagi Anak Play Group Aisyiah Di Kecamatan Kartasura, Sukoharjo". Jurnal Penelitian Humaniora, Vol. 12, No. 2, Agustus 2011: 126-136 (Jurnal Online).

Hamalik, O., (2008). Kurikulum dan Pembelajaran. Jakarta: Bumi Aksara http://ojs.umrah.ac.id/index.php/gantang/i ndex.

Kemendikbud. (2012). Dokumen Kurikulum 2013. Jakarta: Kemendikbud.

Kemendikbud. (2013). Kurikulum 2013. Jakarta: Kemendikbud.

Kemendikbud. (2013). Pedoman Teknis Pembelajaran Calistung di Sekolah Dasar.

Krulik, S \& Rudnick. (1999). "Innovative Tasks to Improve Critical-and Creative-Thinking Skill”. Developing Mathematica; Reasoning in Grades K-12, pp. 138-145.

Kuntarto, E., (2017). "Pembelajaran Calistung". Repository Unja. https://repository.unja.ac.id/cgi/users/hom e?screen=EPrint $\% 3 \mathrm{~A} \% 3 \mathrm{AView} \&$ eprintid $=634$

Kuntarto, E., (2018). "Analisis Tingkat Pemahaman Guru Terhadap Konsep Pembelajaran Aritmatika-Bahasa di Sekolah Dasar". Jurnal Gantang III (2) (2018): 97-108. p-ISSN: 2503-0671.

Maryeni, Rochmiyati, Sasmiati. (2014). Analisis tingkat pemahaman guru sekolah dasar tentang pembelajaran terpadu pada kurikulum 2013, 1-11. Retrieved from http://download.portalgaruda.org/article.p hp? article $=288730 \& v a l=7239 \&$ title $=$ pema haman guru sekolah dasar tentang pembelajaran terpadu pada kurikulum 2013.

Miles, M.B, and Huberman, A.M. (1994). Qualitative Data Analysis, 2nd Ed., p. 1012. Newbury Park, CA: Sage.

Peraturan Menteri Pendidikan dan Kebudayaan (Permendikbud) Nomor 81 A Tahun 2013 tentang Pedoman Pelaksanaan Kurikulum 2013.

Sukmadinata, N.S,. (2006). Metode Penelitian Pendidikan. Bandung: Penerbit Rosda.

Wardhani, S. W., Hasyim, A., \& Rosidin, U. (2015). Evaluasi pembelajaran membaca, menulis, dan berhitung. Jurnal Teknologi Informasi Komunikasi Pendidikan, 2(5). Retrieved from http://jurnal.fkip.unila.ac.id/index.php/JTP /article/view/6227. 